\title{
ELOMAR FIGUEIRA MELLO: UM EDUCADOR DO SERTÃO
}

\author{
Gilmar Leite FERREIRA ${ }^{1}$
}

\begin{abstract}
Resumo
Este artigo tem como fundamento Elomar Figueira Mello: Um Educador do Sertão. O objetivo é interpretar e descrever os conhecimentos e aprendizagens que fazem parte da obra musical do compositor citado. Por meio do método fenomenológico do filósofo Maurice Merleau-Ponty, descrevo e interpreto a música e a poesia de Elomar como um campo de conhecimentos diversos, mostrando que a obra musical e poética, de forma implícita e explícita, apresenta uma proposta educativa envolvendo aspectos culturais, sociais, antropológicos e históricos do sertão da Bahia, a biologia da caatinga e outros aspectos do mundo sertanejo, revelados em toda a sua plasticidade educativa. Considerando os fatores citados, a música, além de afetar a existência humana, possui uma epistemologia própria que, por meio do sensível, educa o olhar e a audição através da experiência estética, propondo uma educação do sujeito que se percebe e percebe o mundo por intermédio da sensibilidade.
\end{abstract}

Palavras-Chave: Elomar. Sertão. Educação. Fenomenologia.

\footnotetext{
${ }^{1}$ Doutor em Educação pela Universidade Federal do Rio Grande do Norte, professor do Departamento de Educação da UFPB (Campus IV) e vice coordenador do grupo de pesquisa Gepedusc (UFPB).

E-mail: poetagilmar@gmail.com.
} 


\title{
ELOMAR FIGUEIRA MELLO: AN EDUCATOR FROM THE BACKLANDS
}

\author{
Gilmar Leite FERREIRA
}

\begin{abstract}
This article has as theme Elomar Figueira Mello: An Educator from the Backlands. It aims to describe and interpret both the knowledge contained in his work and the learning that such knowledge produces. Its methodological reference is Maurice Merleau-Ponty's phenomenology. So, I analyze Elomar Figueira's music and poetry, showing that his work is bearer of an educational proposal that involves cultural, social, anthropological and historical aspects of Bahia's backland, as well as the biology of the caatinga and other features of the backland world. It can be concluded that the music influences the human formation, and it also has an epistemology that, through sensitive experience, educates both the way of observing the world and the exercise of listening. This epistemology proposes an education of the subject who perceives himself and the world through sensitivity.
\end{abstract}

Keywords: Elomar, backlands, education, phenomenology. 


\title{
ELOMAR FIGUEIRA MELLO: UN EDUCADOR DE LA REGIÓN AGRESTE
}

Gilmar Leite FERREIRA

\begin{abstract}
Resumen
Este artículo está basado en Elomar Figueira Mello: Un Educador de La región agreste. El objetivo es interpretar y describir los conocimientos y aprendizajes que forman parte de la obra musical del mencionado compositor. Mediante el método fenomenológico del filósofo Maurice Merleau-Ponty, describo e interpreto la música y la poesía de Elomar como un campo de conocimiento diverso, mostrando que la obra musical y poética, implícita y explícitamente, presenta una propuesta educativa que involucra aspectos culturales. Sociales, antropológicos e históricos de la región agreste de La Bahía, la biología de la catinga y otros aspectos de esa ubicación, revelados en toda su plasticidad educativa. Considerando los factores antes mencionados, la música, además de afectar la existencia humana, tiene una epistemología propia que mediante lo sensible, educa el ojo y el oído a través de la experiencia estética, proponiendo una educación del sujeto que percibe y percibe el mundo a través de la sensibilidad.
\end{abstract}

Palabras clave: Elomar. Región Agreste. Educación. Fenomenología. 


\section{O compositor poeta do Sertão}

Este artigo fundamenta-se na fenomenologia de Merleau-Ponty e outros autores, tendo como campo de reflexão e interpretação o cantador e violonista Elomar Figueira Mello como o poeta educador do sertão. Irei, por meio de um diálogo poético, interpretar e descrever o mundo vivido ${ }^{2}$ do compositor citado que, através da criação poética musical, tem mostrado ao longo dos tempos uma obra trovadoresca e operística, tendo na cultura e na natureza do sertão nordestino a visibilidade estética da expressão poético-musical.

O objetivo do artigo é interpretar e descrever o campo educacional que permeia a obra de Elomar, levando em consideração que não se trata de uma educação familiar e nem escolar, mas sim uma educação da vida, por meio da experiência estética, tendo o sensível como forma de aprendizagem e educação. Nesse sentido, não farei uma exegese da música de Elomar a partir dos princípios técnicos da música, nem muito menos pelo viés dos conceitos linguísticos, inerentes nas letras das músicas. Pensando justamente nos aspectos descritos e tendo conhecimento que existe uma considerável pesquisa sobre o compositor no universo dos pesquisadores no campo da música e das letras, resolvi enveredar no diálogo entre música, literatura, filosofia e educação, entrelaçando conhecimentos distintos, apresentando a proposta educativa que permeia a obra de Elomar.

A contextualização da obra de Elomar configura-se num ato educativo, mostrando os fatos históricos, culturais, antropológicos, sociológicos, a caatinga ${ }^{3}$, a poesia e a música, emoldurando um campo de aprendizagem onde a experiência estética é uma educação tecida na sensibilidade. Nesse sentido, o sertão esboça-se na sua forma distinta de ser, como um lugar que provoca o sensível do compositor, abrindo um horizonte de criação pautado na sonoridade de uma natureza repleta de cantos e movimentos por meio dos animais e do próprio sertanejo. Por isso, torna-se necessário comentar que a lapidação estética de que Elomar se apropria para apresentar uma obra sofisticada é a expressão de um mundo que se apresenta em primeiro plano como algo rústico e de difícil compreensão.

\footnotetext{
2 A expressão Mundo Vivido é uma tentativa de tradução da expressão alemã Lebenswelt, tema primeiro da Fenomenologia, que diz respeito ao mundo pré-reflexivo. O Lebenswelt ganha força com o entendimento sobre a questão da verdade, a partir da obra de Husserl - Investigações Lógicas. Nesta, a verdade não pode ser definida como adequação do pensamento ao objeto, não sendo definida a priori pelo sujeito e nem contemplada na pura exterioridade do objeto. A verdade é definida na evidência da experiência vivida. O vivido não é um sentimento, mas refere-se à percepção como modo original da consciência (NÓBREGA, 1999, p.18).

${ }^{3}$ A caatinga é percebida, sobretudo, por sua fisionomia vegetal extremamente típica, com distribuição pelos Estados do Nordeste brasileiro, estendendo-se do Maranhão ao Norte de Minas Gerais. Com cerca de 01 milhão de quilômetros quadrados, ela foi, nos primórdios da colonização, a primeira dentre as microunidades de paisagem no Brasil a ser submetida a um intenso processo de antropização, sob o efeito da conquista do território pelo homem branco invasor, com sua visão europeizante. Elo importante dessa visão é a ânsia de enriquecimento rápido, pela exploração de recursos naturais e pela submissão das populações autóctones no sentido de obter mão-de-obra-assalariada (MELLO FILHO, 1994-95, p.25).
} 
Elomar é um cantador do povo, um menestrel do sertão, um poeta da caatinga, um bardo medieval, um instrumentista virtuoso, um criador de bodes e ovelhas, um tangedor de gado e um contador de estórias. O vate do sertão é o cronista de um povo humilde e pobre que vive escondido nos rincões do sertão do Nordeste brasileiro (MAURÍLIO, 1984).

Arquiteto por formação e criador de bodes e ovelhas por opção, o cantador resolveu transformar em lendas poéticas musicais as muitas estórias que ouviu dos mais velhos, durante a infância, às margens do Rio Gavião, em Vitória da Conquista, Sudoeste da Bahia. Avesso ao mundo dos urbanos, principalmente das grandes metrópoles, Elomar se afastou da suposta civilização urbana para viver na caatinga, ao lado dos animais e do sertanejo humilde, tornando-se um cronista de seu povo, sendo um educador do lugar, contando e cantando através da sua singular música os fatos e acontecimentos da sua terra (MAURÍLIO, 1984).

A criação poética musical ambientada no sertão é quase imemorial! Nela, o mítico e o místico se expressam nas cantigas, óperas e sinfonias. As raízes da criação são ibéricas, medievais, barrocas, renascentistas, clássicas ${ }^{4}$, orientais e sertanejas. O poeta cantador aproxima os elementos da música europeia e trovadoresca para falar do sertão, dando um tratamento sofisticado ao homem sertanejo. A virtuosidade da obra de Elomar reveste-se de uma beleza poético-musical que engradece e universaliza o telurismo do sertão nordestino, lugar repleto de adversidades naturais e de manifestações humanas (MAURÍLIO, 1984).

O cantador poeta por meio de um virtuosismo musical erudito investe na tradição popular, fazendo de maneira diferente de Heitor Villa-Lobos e de Amadeus Wolfgang Mozart, entre outros clássicos que buscaram na cultura popular o aporte para tornar eruditas ${ }^{5}$ as suas composições. Elomar faz o caminho inverso. O seu trabalho já nasce com as roupagens da erudição, devido estudos em curta duração da música e da própria percepção de interpretar o sertão a partir de uma visão clássicamedieval. O poeta do sertão, antes de tudo, é um homem da terra, acostumado com os ritmos da vida do homem camponês, pois o ofício de agricultor e de vaqueiro faz parte da sua existência.

O poeta relata os dramas seculares das grandes secas, como o êxodo, a fome e a miséria dos sertanejos; fala das tragédias de casamentos não realizados, da festa de São João, das donzelas sertanejas, dos desafios dos poetas repentistas, do vaqueiro, da maneira dialetal do povo falar e da

\footnotetext{
${ }^{4}$ A forma de compor e de tocar a música do sertão nordestino tradicionalmente representada por Luiz Gonzaga e seus parceiros, era emoldurada ou acompanhada por uma sanfona, uma zabumba e um triângulo (às vezes tinha um pandeiro). Elomar, por ter tido, por um curto espaço de tempo, aula de música numa escola acadêmica, apropriou-se da influência dos compositores conceituados como clássicos. Então, a criação musical do compositor apresenta a linguagem da música sinfônica e operística, típica dos países europeus (nota do autor).

${ }^{5}$ Embora haja uma distinção entre popular e erudito, não se sabe ao certo onde termina o popular e começa o erudito (ZUMTHOR, 2005).
} 
relação do homem com Deus. A influência da tragédia grega perpassa pela obra do poeta do sertão, em que o belo feminino é sinal de tragédia, desavença e morte entre os homens.

Na sua obra magnífica, o cantador transcende o medieval quando o poeta compositor mergulha na Idade Média, revelando o universo da cavalaria, com seus cavaleiros, menestréis, reis, rainhas, príncipes, princesas e vassalos (MORAIS, 1973). Mas, é no sertão que Elomar torna a obra poética musical mais enraizada com a sua identidade cultural. Nas composições, sempre há uma súplica do cantador para que o homem do sertão não deixe o lugar onde reside, mesmo nas condições mais adversas. O poeta afirma que um dia a chuva voltará e tudo renascerá; mas a saída do homem do sertão para outros cantos, quando retorna para seu lugar de origem, traz todo um corpo de valores culturais diferentes, perdendo assim a sua identidade sertaneja (MAURÍLIO, 1984).

Embora sua obra mostre, através do épico, as tragédias do universo sertanejo, em que a morte e as desventuras fazem parte do cotidiano, ela tem um compromisso profundo com a vida, mostrando a força e a resistência do homem do sertão, numa terra repleta de desafios constantes. É justamente nesse paradoxo que o sertão se constitui como um lugar de aprendizagens em movimentos contínuos. Tomado por essa atmosfera, Elomar tece na sua obra musical sentidos e significados de uma educação vivida no cotidiano, aprendida nas constantes relações diárias entre homem, natureza e cultura em que o diálogo arquiteta pilares de um aprender que se faz pelas observações e trocas permanentes. Nesse sentido, a fenomenologia de Merleau-Ponty tem no seu arcabouço argumentativo o mundo vivido, não como um puro comportamento, mas sim como uma atitude de envolvimento com as coisas da vida na sua ampla plasticidade de movimento, de expressão e de comunicação.

\section{A criação e a educação que emerge do sertão elomariano}

Os gemidos da terra durante as grandes estiagens; os ecos do ruflar dos ventos anunciando mais desolação; os berros dos bodes e das ovelhas, o canto dos grilos, dos sabiás e demais pássaros e insetos penetram no corpo de Elomar, movimentam-se, ficam tácitos no seu espírito, afetam a dimensão sensível e, quando o poeta-cantador entra em êxtase pelos caminhos da experiência estética, emergem da sua sensibilidade poética musical construções de acordes, de versos, de cantos, de harmonias, manifestados em cantigas trovadorescas, óperas e sinfonias.

As manifestações da natureza se transformam em música e poesia pela capacidade do compositor do sertão em emergir do sensível os cantos dos pássaros, o som dos insetos, o barulho dos ventos, a música das chuvas e as cantigas dos festejos populares. A empatia de Elomar com o 
sertão interliga a música codificada de forma orquestral num amalgama estético, dando um tratamento sofisticado a uma música que vem da natureza, da vida simples do homem do sertão, das tragédias, da aridez, transformando-a numa linguagem erudita.

O mundo vivido e percebido por Elomar é a capacidade sensível do cantador em perceber e sentir as coisas que estão ao seu redor e transformá-las em um campo de composições clássicas, com toda a carga de simplicidade que têm as coisas do sertão. O mundo árido e verde do sertão transforma-se em notas musicas e poesias numa dimensão sentimental que agiganta as coisas imperceptíveis ao olhar comum. O que Elomar faz é transformar num logos estético o mundo cultural da sua existência, interligada com as coisas da natureza e da vida humana no sertão.

De acordo com Merleau-Ponty (2004, p 01):

O mundo da percepção, isto é, o mundo que nos é revelado por nossos sentidos e pela experiência de vida, parece-nos à primeira vista o que melhor conhecemos, já que não são necessários instrumentos nem cálculos para ter acesso a ele e, aparentemente, basta-nos abrir os olhos e nos deixarmos viver para nele penetrar. (PONTY, 2004, p. 01)

É penetrando nas coisas do mundo que podemos ter a capacidade de dar-lhe um estatuto ontológico de um único Ser constituído de diversas partes e aproximar-nos da concepção de que nada se encontra isolado, mas sim existe uma inerência daquilo que percebemos e sentimos. Nesse sentido, a filosofia de Merleau-Ponty abre o campo para uma compreensão de que não estamos sós no mundo, mas em uma complexa rede de ligações, na qual interagem todas as formas de vida. O vivido não é um sentimento, é a abertura do corpo vivo por meio da percepção, na qual o corpo é sujeito e objeto ao mesmo tempo, num intercruzamento, fundamentado na noção da mão que toca e é tocada, pois não existe um sujeito e um objeto, mas dois seres que são ativos e passivos na mesma ação, expressando a linguagem que surge a partir do tocante e do tocado (MERLEAU-PONTY, 1999).

Assim, vamos encontrar no processo criativo de Elomar a relação com o sertão, constituída pela percepção sensível que faz emergir uma imensa produção poético-musical. O sertão com seus movimentos de natureza e cultura penetram no sensível do poeta operístico, e as vozes da caatinga e do homem sertanejo, como o vaqueiro e o agricultor, mergulham no seu coração, criam acordes, melodias, poesias, escalas e harmonias que se expressam numa linda sinfonia, criada por meio das mãos rudimentares do velho trovador-agricultor-vaqueiro do sertão. Segundo Barroso (1923, p. 15), “e por isso o grilo do coração do trovador sertanejo, ao dedilhar a sua viola, no enluarado pátio da fazenda, diante da noite clara, que se estende à face imensa do sertão agreste”.

Nas cordas do coração de Elomar existem sonoridades latentes de um sertão que o poeta cronista ouviu dos mais velhos, quando era criança, nas margens do Rio Gavião. Estórias de 
tragédias por questões amorosas são transformadas em óperas, nas quais há um canto lírico épico que revela o sertão primitivo, pautado no campo das relações entre os humanos do sertão, com seus valores éticos e morais, tão consistentes e indeterminados como a terra árida em que habitam. No entanto, Elomar tem sua maneira peculiar de sentir as coisas do sertão, porque a percepção é uma atitude do sujeito com o mundo.

Ao ouvir a música de Elomar, pode-se perceber uma autobiografia, pois a vida desse poeta do sertão faz-se pela escritura da natureza no seu corpo sensível, onde estão escritos os fatos e acontecimentos da terra árida, repleta de uma linguagem contingente que se faz e refaz a cada estação do ano. Os escritos do sertão habitam a expressão estética do compositor por meio de uma sonoridade que traça o autobiográfico de uma existência escrita de acordes, poesias e harmonias, num ambiente repleto de musicalização.

De acordo com Andrieu, (2015, p 52):

Autobiografar-se, seria suficiente pelo fato de justificar-se pela sua origem ou pelo menos pela originalidade do olhar? Ao relativizar a extremidade geográfica a produção in loco é incarnada, exprimindo o meio ambiente do terreno, a intensidade do território e a autenticidade do agente. O corpo deve portar o traço da sua originalidade para não se apagar, não aparecer muito neutro. (ANDRIEU, 2015, p.52)

A escrita poética musical de Elomar é in loco, pois a emersão do mundo-sertão transubstancia o poeta compositor numa expressão corpórea que revela os movimentos da natureza sertaneja e da vida humana do sertão, quando seus dedos deslizam no corpo do violão e sua voz emerge os cantos de uma terra repleta de sons adversos, que apresentam a alegria dos animais (entre eles, o homem), dos insetos (presença da chuva) ou através dos seus cantos tristonhos e solitários devido às grandes estiagens. Esse movimento da natureza, em tons paradoxais, como se fossem dissonantes, afina a sensibilidade do poeta-cantador, lapida a percepção e capta as mais diversas linguagens dos seres da caatinga, despertando do coração do poeta-cantador um painel estético cultural.

É justamente no campo do vivido que Elomar se mostra como um educador, sem apresentar conteúdos programados e objetivos estabelecidos, mas expressando uma música que possui um imenso campo de aprendizagens, as quais são possíveis de serem apreendidas por meio da experiência sensível. Nessa concepção, torna-se necessário abrir a percepção para entrar nas melodias, nos cantos, nas palavras, para descobrir o imenso corpo do sertão, com suas aporias e contingências.

Moldado pelo espírito da terra, Elomar veste-se de um telurismo profundo, tornando difícil separar o mundo-vida do compositor em relação às coisas que estão no sertão. Seu amor pela terra, pelos animais, pelos vegetais e pelo homem do sertão encarna a sua existência, e o compositor passa a impressão de que é feito de terra, de música e poesia, transportando, para seus cantos operístico, 
sinfônico e trovadoresco, o perceptível do seu dia a dia ou das estórias dos mais velhos, ouvidas na infância distante. Essa inerência com o lugar se transforma num amor profundo pela terra. Nos seus cantos há sempre uma súplica ou alerta para que o homem do sertão não deixe o lugar onde reside, pois geralmente a saída para outras terras, resulta na perda da identidade cultural por causa das pressões da cultura urbana ou de outros lugares distantes do sertão. Nesse sentido, o poeta-cantador irmana a terra, abraça-se com o sentido de amor ao lugar, mesmo diante da partida da amada, como podemos perceber na sua música “Canção da Catingueira” (Mello,1973).

Maria, mĩa ${ }^{6}$ Maria, Num faça'ssim cumigo não! Olha que as chuvas de janeiro Ainda num caíram no chão Olha que as chuvas de janeiro Ainda num caíram no chão Maria, mĩa Maria, Num faça'ssim cumigo não! Olha que as flores do umbuzeiro Ainda num caíram no chão. Maria, mĩa Maria,

Meu anjo de pés no chão, Quano tu fores pela'strada

Se ouvires a canção Se do fundo das águas

Ouvires a canção

Não tenhas minha amada,

Temeroso o coração,

Pois são saudades,

São minhas mágoas

Que contigo também vão.

Maria, mĩa Maria,

Não vá simbora inda não Esqueça o xale, esqueça a rede,

Esqueça até meu coração,

Mas não te esqueças, ó Maria,

Deste nosso pedaço de chão.

O amor a Maria na música de Elomar, intitulada "Canção da Catingueira”, não consegue superar o amor à terra que emerge do cantador em relação ao sertão. Nos primeiros versos, o poetacantador suplica para que ela não o deixe, pois as esperadas chuvas de janeiro ainda não caíram e os umbuzeiros não perderam as suas flores; então, existe a esperança na alma do sertanejo e nas experiências com relação à natureza que, no período citado, pode chover fazendo a terra germinar alimento para todos os seres vivos do sertão. Mesmo suplicando para que a mulher amada não deixe a terra, Maria, de pés descalços, devido à pobreza, continua sua jornada pela terra árida, em busca 
de um lugar onde a chuva seja constante. Na cena versificada, operística, sobre a retirada de Maria, o cantador poeta expressa seu profundo lirismo cantante, dizendo à amada que os sons das águas, são os sons das suas mágoas, fragilizadas e reveladas através da dolente canção, ofertada a Maria. Nesse instante, o cantador percebe que é vã a súplica cantante, pois a mulher amada segue sua jornada. Diante disso, o menestrel do sertão abdica do amor a Maria e até a preocupação com os bens pessoais da mulher. Nesse instante, o amor do poeta cantador com relação à terra transcende todos os outros apegos materiais e a força do romantismo, quando ele, no proscênio, pede à amada que esqueça tudo, até o próprio cantador, mas não esqueça da terra que está deixando.

A pedagogia de amor à terra, fundamentada na educação do cuidar, é bordada de aprendizagens e ensinamentos, constituindo Elomar como um educador do sertão. O viés do sensível como ato educativo, a cultura como aprendizagem, perpassam pela obra do poeta compositor, formando uma tessitura de valores educacionais, pautados no amor do homem à terra em que habita.

A música por si mesma tem um enorme campo educativo a partir da sua própria epistemologia, como ritmos, harmonias, melodias, arranjos, interpretação, escalas, notas e composição. Esses campos mostram um imenso conteúdo pedagógico repleto de variações, andamentos e movimentos. Nessa perspectiva de aprendizagem e educação, pode-se trabalhar em sala de aula os diversos estilos musicais que fazem parte do grande mosaico estético-cultural do Brasil.

Ter conhecimento dos vários ritmos da musica brasileira é saber como dançamos, nos expressamos e nos comunicamos, dada as diversas formas de linguagens que compõem a configuração de um país que no seu processo de colonização multicultural e multirracial revela o quanto temos que aprender e nos educar por intermédio da música.

Educar a audição é de fundamental importância devido a sociedade contemporânea estar vivendo uma espécie de ditadura das imagens, perdendo a capacidade de explorar e viver os outros sentidos. Uma música deve ser ouvida várias vezes, procurando compreender sua constituição de composição, de conhecimento cultural e de valor estético. Nenhuma obra artística esgota-se no processo de apreensão e conhecimento. A percepção, mesmo em sua enorme disposição de penetrar nas coisas e de habitá-las, sempre deixa algo oculto e imperceptível ao primeiro olhar. Por isso, é precisa ouvir como se fosse a primeira vez, como se estivesse inaugurando o ato de ouvir, deixandoo aberto às diversas significações ainda não apreendidas.

Segundo Heller (2006, p. 36): 
Nesse sentido a fenomenologia prestou-nos um enorme favor ao apresentar como método e não se contentar nunca com os conhecimentos descobertos e guardados do passado: a compreensão deve ser sempre nova e atual. Existe uma história, porém ela sempre deve começar de novo. A fenomenologia não pode ter seguidores porque é preciso sempre chegar a novas visualizações, a novas análises do fenômeno. O fenômeno não pode ser conservado, ele tem que ser sempre revisto, sempre recriado (HELLER, 2006, p. 36).

Explorar o campo musical por meio da fenomenologia nos coloca em um movimento constante, pois ambos são constituídos de mobilidade filosófica e epistemológica que não se fecham numa síntese final, mas estão sempre criando novos sentidos e significados. A arte musical possui uma grande constituição de composição como já foi dito antes. Por isso, revisitar uma determinada música, ou uma obra musical, dilata a percepção auditiva, abre os canais de compreensões que não estão dados pelos conceitos de padrões estéticos e culturais definitivos. Nesse sentido, torna-se necessário levar a música para sala de aula com uma proposta da apreensão livre e da interpretação individual. No entanto, cabe ao professor, junto com os alunos(as), fazer uma contextualização estética, cultural e artística. Dessa maneira, caberá ao aluno(a) analisar e avaliar a música que não é veiculada nas mídias tradicionais e a que faz parte do grande processo de massificação, geralmente atrelado a interesse capitalista, de consumo e de alienação.

De acordo com Freire (2011, p. 67),

O processo de orientação dos seres humanos no mundo envolve não apenas a associação de imagens sensoriais, como entre animais, mas, sobretudo, pensamento-linguagem; envolve desejo, trabalho-ação transformadora sobre o mundo, de que resulta o conhecimento do mundo transformado. Este processo de orientação dos seres humanos no mundo não pode ser compreendido de um lado, de um ponto de vista puramente subjetivista; de outro, de um ângulo objetivista mecanicista. Nesta orientação do mundo só pode ser realmente compreendido na unidade da dialética entre subjetividade e objetividade. Assim entendida, a orientação no mundo põe a questão das finalidades ao nível da percepção crítica da realidade (FREIRE, 2011, p. 67).

O educar por meio de reflexão crítica da realidade no campo da arte musical desenvolve no educando a capacidade de escolha de determinado estilo de música veiculada nos meios de comunicação de massa e a que fica à margem da comunicação tradicional, portadora tecnológica de grande poder de alcance audiovisual. Por isso, o professor deve ser um educador aberto, capaz do diálogo e de criar questões para que os educandos possam refletir sobre o interesse e determinações no campo do consumo artístico-musical. Nesse sentido, deve-se propor uma educação libertadora que proporcione ao educando a sua autonomia no sentido reflexivo e dialógico.

Além de propor uma educação autônoma e crítica-reflexiva, a música desenvolve o ato de perceber por meio da sensibilidade. Essa abertura do sujeito, que se percebe e percebe o mundo por 
meio da experiência estética, põe em reversibilidade o sentido de objeto e sujeito num intercruzamento de afetos em que não existe o sujeito isolado contemplando a música, mas sim, música e ouvinte em um ato só, em que se confundem ambos como seres de uma só experiência. Por isso, a percepção deixa de ser um mero comportamento para ser um intersubjetividade, num diálogo permanente entre o compositor e o ouvinte.

De acordo de Heller (2006, p. 36):

Nosso contato com a coisa deve ser um contato "com a coisa", não com a "ideia da coisa” (daí a insistência fenomenológica de um retorno 'às coisas mesmas'). Aliás, a palavra "contato" é muito interessante para os propósitos desse trabalho, pois contém a ideia do sentir como percepção tátil: “com tato”. Não se trata, portanto, de uma tentativa de representação do fenômeno, mas antes de uma intuição, de uma compreensão física, corpórea, motriz (HELLER, p. 36).

Para compreender o sertão e vivenciá-lo, torna-se imprescindível a participação do corpo e da intuição, despertando a subjetividade que se estende na atitude intersubjetiva, revelando que não existe o sujeito separado do sertão, mas sim, dois corpos que trocam afinidades, conhecimentos e aprendizagens. Nesse sentido percebemos que nos versos e na reflexão sobre a relação de Elomar com o sertão, o entrelaçamento do poeta compositor com o mundo vivido faz emergir da dimensão sensível cenas e versos de uma canção dolente, romântica, telúrica e saudosista. Tomado pelo profundo amor ao sertão, Elomar expressa do seu corpo-terra uma configuração entrelaçada do homem com o lugar, transformando-se em um único Ser. Essa ontologia sertaneja, revelada por intermédio da música, transubstancia uma metafísica encarnada, onde o vivo e o vivido são seres de uma mesma revelação.

Segundo Heller (2006, p. 91):

Não expressamos 'algo' 'usando' o corpo: o corpo se expressa; a expressão organiza-se ela-mesma o corpo, numa totalidade indivisível entre música e corpo. A técnica não nos possibilita o acesso a um evento musical: a intenção musical e a ação musical fundam-se mutuamente numa relação de não dependência. Som e gesto estão envolvidos num mesmo todo, sendo fenômeno expressivo justamente esse todo, e não uma somatória de partes numa relação casual; trata-se de um saber que se efetua por síntese, não por agregação. Fazer música não é manipular uma máquina, produzir um som não é ter o som como fim (HELLER, 2006, p. 91).

A música não se faz como algo dado e programado, ela escorre sua sonoridade por dentro do corpo, pelos canais da sensibilidade, sem manipulação laboratorial, com um fim estabelecido. Partindo do princípio de que a criação musical é um arrebatamento da corporeidade, uma afetação do mundo sobre o compositor no processo criativo, compreende-se que o sertão em toda a sua plasticidade de natureza e cultura empresta suas significações e sentidos a Elomar. Este poetacantador re-significa o mundo sertão por meio de uma música repleta de símbolos e signos 
estéticos, os quais são: o mugido do gado, o bodejar de um bode, o cantos dos pássaros e demais manifestações do sertão, transformados em música e poesia. A emersão flui de maneira espontânea, pois os movimentos do sertão estão latentes no corpo do poeta-cantador, esperando o momento de a inspiração estesiológica tocar as cordas do sentimento, afinar o sensível da criação, para então o mundo vivido e percebido surgir de maneira encantadora. Elomar não inventa nada. Isso é coisa de laboratório de sons e letras. Ele coloca na música o que ele percebe.

Segundo Heller (2006, p. 117), "Perceber é um ato que cria um vínculo inseparável entre o olhar e o olhado, de onde podemos dizer que a percepção é necessariamente, um ato de criação desse vínculo e desse enlace”.

O entrelaçamento de Elomar com o mundo natural e com a cultura fundamenta-se na sua percepção como um fundo das coisas que fazem parte da vida do compositor. Esse fundo imemorial não perceptível ao olhar comum ou apressado é constituído de uma memória inscrita no seu corpo, fazendo-se atos de uma criação musical tecida na pele por meio das agulhas da experiência estética, deixando no tecido corporal as cores das flores da caatinga, os "fuxicos" do pássaro lavadeira à beira de um riacho, as prosas dos vaqueiros nos currais, as rezas de uma velha beata com os olhos tomados pelo glaucoma, o mugido de um touro apartado do rebanho, a cantiga de um imponente sabiá no galho de alguma árvore ao redor da velha casa da fazenda e nas demais manifestações que fazem parte da vida do cantador do sertão.

Bordado de várias significações, o sertão cria outros sentidos quando Elomar em uníssono com o mundo vivido canta por meio da sua voz de barítono um mundo em constante transformação, pois o sertão nordestino, devido as suas condições paradoxais de clima, está sempre em movimento. Esse fluxo ou “elã vital” (BERGSON, 2015) contínuo é o que torna a obra poético-musical de Elomar inesgotável e em movimento. A cada dia, o poeta in loco percebe diversos movimentos da natureza sertaneja e da cultura, ora se revelando, ora se ocultando. Então, o perceber sensível do poetacantador vai captando as linguagens do seu lugar, internalizando-as, criando uma nova experiência estética, formando um fundo de expressões nas quais o sertão se destaca no contexto da sua obra.

De acordo com Merleau-Ponty (1999, p. 6), “a percepção não é uma ciência do mundo, não é nem mesmo um ato, uma tomada de posição deliberada; ela é o fundo sobre a qual todos os atos se destacam e ela é pressuposta por eles”.

A percepção não é uma posição do corpo pronto para se apossar das coisas do mundo de forma determinada. Ela é o movimento do corpo indeterminado que se liga e habita o perceptível, infiltra-se nele, mesmo sem ela se dar conta. Então, nem Elomar nem as coisas do sertão têm uma 
consciência determinada ou algo determinante que funde a relação. Ela acontece quando menos se espera, nos intervalos e nas ações tácitas, nas curvas ou no avesso do que não foi percebido. Dessa maneira, o sensível move-se, ganha amplitude, amplifica-se e, de repente, Elomar transcende do despertar sensorial uma carga de expressão que se realiza num logos estético.

Afetado pela condição sensível, Elomar penetra na geografia do lugar e no sertão do seu espírito, pois antes de qualquer reflexão, ele é um homem do sertão. Essa condição de existência possibilita ao poeta-cantador ser a voz da caatinga. Por isso, escutam-se nos seus cantos trovadoresco, operístico e sinfônico os ecos da natureza sertaneja e da vida humana no sertão. Muitas das suas melodias são os sons que o sertão emite, seja na voz da natureza ou de uma manifestação humana. As melodias têm um tom de saudosismo, de uma esperança que se agarra em qualquer coisa, de uma melancólica tarde de verão, quando o sertanejo fica mais introspectivo e religioso, curvando-se aos pés da Ave-Maria. Nesse sentido, o sertanejo, de acordo com Cunha (2003, p. 88):

Não é mais indolente, incoercível ou impulsivo violento, vivendo às disparadas pelos arrastadores. Transcende a sua situação rudimentar. Resignado e tenaz, com a placabilidade superior dos fortes, encara de fito a fatalidade incoercível; e reage. O heroísmo tem nos sertões, para todo o sempre, as perdidas tragédias espantosas. Não há como revivê-las ou episodiá-las. Surgem de uma luta que ninguém descreve - a insurreição da terra contra o homem. A princípio, este reza, olhos postos na altura. O seu primeiro amparo é a fé religiosa. Sobraçando os santos milagreiros, cruzes alçadas, andores erguidos, bandeiras do Divino ruflando, lá se vão, descampados em fora, famílias inteiras - não já os fortes e sadios senão os próprios velhos combalidos e enfermos claudicantes, carregando nos ombros e na cabeça as pedras dos caminhos, mudando os santos de um a um para outros lugares (CUNHA, 2003, p. 88).

O poeta-cantador Elomar, igual a quase todo sertanejo, é um homem profundamente religioso. Essa condição da tradição cultural do sertão permeia a vida para suportar o indeterminado que a natureza apresenta. Por isso, o sertanejo apega-se à religião como a primeira e última esperança para dias melhores. Mas, impreterivelmente a seca, como condição da falta de chuva, ameaça a vida catingueira. Geralmente, a seca sempre vem em períodos longos. Esse movimento climático do semiárido inspira o poeta-cantador. Por isso, vamos encontrar em toda a sua obra a narrativa poético-musical sobre os dramas das secas, como é o caso da sinfonia intitulada: Incelença pra terra que o sol matou (Mello, 1981, p. 03):

Levanto meus olhos

Pela terra seca

Só vejo a tristeza

Qui disolação

E u'a assada branca

Fulorano o chão.

E o passu-Rei, rei do manjá 
Deu bença ${ }^{7}$ à Morte pra avisá

Prus urubu de otros lugá

Qui vince ${ }^{8} \operatorname{logo}$ pra jantá

Do Rei do Fogo e do lũá.

Do lũá sizudo ${ }^{9}$

Do Ri Gavião

Mais o sol malvado

Quemô os imbuzeiro

Os bode e os carneros

Toda a criação

Tudo o sol quemô.

É qui tão as era

Já muito alcançada

A palavra vea ${ }^{10}$

Reza qui havéra

De chegá um tempo

Só de perdedera.

Qui só havéra de iscapá

Burro criolo ${ }^{11}$ e criação

Qui pra cumê levanta as mão

É qui um irmão pra otro irmão

Saudava c'essa pregação.

Lembra qui a morte

Te ispera meu irmão

E o sol da má sorte

Rei da tribusana ${ }^{12}$

Popô sussarana ${ }^{13}$

Carcará ladrão

Isso o sol popô.

Mais num há de sê nada

$\mathrm{Na}$ função das bestas

Purriba ${ }^{14}$ da festa

Pirigrina a fé

Sei que ainda resta

Cururu-têtê ${ }^{15}$

Na minha casa hai um silenço

A tuia pura e o surrão penso ${ }^{16}$

$\mathrm{O}$ meu cachorro amigo menso ${ }^{17}$

Deitô no chão ficô in silenço

E nunca mais se alevantou.

\footnotetext{
${ }^{7}$ Benção

${ }^{8}$ Que viesse

${ }^{9}$ Calado

${ }^{10}$ Velha

${ }^{11}$ Tipo de burro

${ }^{12}$ Tristeza

${ }^{13}$ Onça

${ }^{14}$ Por cima

${ }^{15}$ Tipo de sapo

${ }^{16}$ A cuia pura e o surrão pendente simbolizam o pouco alimento na casa do sertanejo

${ }^{17}$ Imenso
} 
Inté os olhos d'água

Chorô qui secou

E o sol dessas mágua

Quemô os imbuzero

Os bode e os carneros

Toda a criação

Tudo o sol quemô

No Ri Gavião

Tudo o sol quemô

Toda a criação.

A poética letra em dialeto sertanejo, cantada por Elomar e acompanhada pela delicadeza musical da Orquestra Sinfônica do Estado da Bahia, revela cenas trágicas do sertão diante da seca. A tristeza, a desolação, a ossada branca de um animal que morreu de fome, a presença do urubu como ave agoureira, o sol como rei do fogo, a profecia de um tempo de perdas, a ameaça da ave de rapina e da onça (poupados pelo sol), a morte silenciosa do cachorro, a secura dos olhos d’água (nascente), o sol queimando os bodes, os carneiros e o umbuzeiro revelam a tragédia do sertão durante a seca. Diante disso, o sertanejo reza e se agarra na previsão dos proféticos animais do sertão. Como o sertanejo é um homem em completa relação com a natureza, resta para ele a experiência perceptiva com relação ao cururu-têtê, uma espécie de sapo que prevê se o ano será bom ou não de chuva. Essas cenas poéticas cantadas por Elomar são relatos e testemunhos da infância distante, quando o poeta-cantador ouviu dos mais velhos sobre os dramas da seca de 1890, fazendo multidões de sertanejos emigrarem para outras terras em busca de salvação.

Entrelaçado com os fenômenos do sertão, como as estórias que ouviu no passado distante ou os ecos da natureza sertaneja, Elomar torna-se o sujeito da percepção. Mas, o movimento perceptivo não repousa em si como uma síntese final. Ele ganha sentidos e constrói significados como campos de expressão. “Assim, não se trata mais de considerar o sujeito que percebe, mas o fenômeno da expressão” (NÓBREGA, 2015, p. 68). O quiasma Elomar-Sertão manifesta-se e se expressa na música e na poesia do compositor citado. Nesse sentido, o campo de expressão se fundamenta no que o sertão tem mais de singular e plural. Nas cantigas, sinfonias e óperas, os fenômenos do sertão são tingidos pela dimensão sensível de Elomar. Nesse enleio, as imagens da natureza e da cultura formam um grande painel de expressão, sendo possível perceber os movimentos dos animais da caatinga, os da criação doméstica, como os bodes, os carneiros, o gado, o cavalo e as tradições populares; mostrando o imenso tecido expressivo do sertão. De acordo com Nóbrega (2015, p. 104): “a fenomenologia sensível é profundamente marcada pelo encontro do olhar com a significação, processo em que não há separação entre expressão e o expresso, o ato e a significação”. 
A dimensão sensível de Elomar é a abertura que impregna no tecido carnal os símbolos e signos do mundo vivido. Tomado pela afetação dos fenômenos naturais e da cultura, em Elomar, antes mesmo da reflexão, encontra-se em seu corpo o sertão em toda a sua plasticidade. O “Ser Bruto” (MERLEAU-PONTY, 2000), que é o ser da criação, o qual antecede o pensamento e se faz presente no ato pré-reflexivo, investe nos sentidos do poeta-cantador o impulso da criação, e o velho menestrel do sertão é tomado por uma estesiologia que move o ato criativo para a elaboração de uma música que tem o som, as cores e os movimentos da cultura e da natureza sertaneja.

Segundo Ferreira (2018, p.161):

O corpo do poeta sensibilizado pelo mundo vivido sente a poesia expandir a sua existência, como o sol ao nascer, clareia a imensidade da natureza. Cada gotícula de sensibilidade que banha o corpóreo do poeta é a força visceral que explode na natureza e toca-o, transformando-se em poesia. No sertão, a poesia se faz presente em vários lugares e dimensiona as relações humanas pelo viés da sensibilidade. Ela clareia o sertão com os fulgores da simplicidade, fazendo-se existir de forma espontânea e natural. O seu veio inesgotável surge das imprevisibilidades das relações humanas, do quiasma humano e natureza que, por meio da transubstanciação, faz o ser humano mostrar-se através das palavras, da fauna e da flora. (FERREIRA, 2018, p. 161)

Afetado pelos movimentos da natureza, do corpóreo de Elomar emerge um campo de movimentos pautado nas cores verde ou cinzenta da caatinga, tornando possível perceber, por meio de sua poética musical, uma orquestra afinada de pássaros cantantes, celebrando a chegada da chuva ou se lamentando com a presença da seca, quando as árvores hibernam e ficam decaídas, expressando um sertão fantasmagórico, numa cena trágica que funda o sertão como um lugar épico, repleto de contradições, de paradoxos, de tragédias, onde as coisas aparentemente afastadas estão unificadas num movimento uno que forma a ontológica expressão do sertão, revelada na poética musical de Elomar.

Os córregos, os riachos, as árvores, os aboios do vaqueiro, a ladainha das rezadeiras, as preces das beatas religiosas, os presságios apocalípticos dos fins dos tempos, as incelências (cantos de morte) para alguém que morreu, o mugido do gado, as cantigas de um grilo solitário, os desafios dos poetas repentistas, a beleza feminina como tragédia, o êxodo do sertanejo, os folguedos populares, a fé inabalável da religiosidade do sertanejo, o homem do sertão perdido no mundo urbano: são signos e símbolos vivos do sertão, os quais estão no mundo vivido do poeta-cantador, afetado sensivelmente e transubstanciado por meio da criação, revelando ontologicamente a poesia e a música, através dos cantos trovadorescos, das óperas trágicas e das sinfonias delicadas, o universo clássico-erudito de um lugar mosaico, repleto de natureza e de manifestações humanas. 
É neste mundo diverso, complexo e sempre em movimento que Elomar tece um conhecimento não dado, mas revelado por meio de um logos estético, emoldurando o sertão como um campo de aprendizagens constantes e de uma criação de sentidos e significados que transformam a existência, tornando o homem mais preparado para compreender e viver em um lugar de excessos e de faltas.

A educação do sertão está implícita e explícita na obra de Elomar. Ensinamentos e aprendizados tecem e transcendem na sua música valores, sentidos e significados de um sertão imemorial. Se não fosse o apertar da memória do velho trovador do sertão em resguardar fatos e acontecimentos do seu lugar, desde a infância distante, muitos acontecimentos poderiam se perder, pelo aspecto da oralidade, típica da comunicação dos sertanejos.

O aspecto sertanejo e a própria capacidade perceptiva de Elomar formam o mosaico humano, estético, cultural e natural de uma educação tecida nas aprendizagens das relações constituídas de afetos, de compartilhamentos e de vivências que se realizam em um aprendizado contínuo, mostrando que a ciência do aprender e apreender se configura nas trocas e experiências educativas.

\section{Considerações Finais}

Esta pesquisa em forma de artigo moveu meu entusiasmo e reforçou a satisfação em interpretar Elomar Figueira Mello como educador do sertão. Encantado pelo seu modus vida e pela poesia e música que compõem as dimensões da criação trovadoresca, operística e sinfônica, como pesquisador, tive o cuidado de não ser contaminado pela extrema paixão pelo que o compositor representa e pelo que ele tem criado por meio da música e poesia. Então, meu olhar teve o cuidado em não se acostumar com o que representa Elomar e sua música. Nesse sentido, tornou-se necessário olhar como se fosse a primeira vez, sempre em busca de novos sentidos e significados com relação ao que compõe o mundo poético-musical de Elomar. Os caminhos são muitos, as veredas estão abertas, o horizonte aponta novas descobertas e outras percepções para um sertão elomariano, moldado pela delicadeza e sensibilidade de um homem feito de uma natureza singular e de uma cultura diversificada que se expressa e se comunica por meio da criação poética musical.

A música de Elomar é um campo de aprendizagens permanente, onde estão os aspectos da cultura sertaneja, as questões sociais do sertão, o conhecimento biológico da caatinga, as histórias do êxodo sertanejo e a sua vida trágica nos grandes centros urbanos, os fundamentos do cristianismo e do velho testamento; enfim, a poética musical de Elomar emoldura um painel de conhecimentos que estão incorporados no sertão. Além disso, a arte poética musical educa a sensibilidade, tornando o 
sujeito da aprendizagem mais sintonizado consigo mesmo e com o sertão, desenvolvendo, por meio da experiência sensível, um melhor sentido humano de ser e estar no mundo.

As veredas (no sentido de caminhos) da obra elomariana nos remetem a uma educação não dada a uma pura concepção do sentido tradicional da educação escolar, com seus conteúdos programados e objetivos estabelecidos, muitas vezes sintonizados em relação às questões cognitivas. O sentido educacional da obra de Elomar é a tessitura no campo de uma educação tecida através da experiência estética que a música e a poesia do compositor proporcionam, como uma maneira de compreender o sertão de forma subjetiva, pelos fios do sujeito que se percebe e percebe o mundo por intermédio da sensibilidade.

O sertão como um campo amplo mostra a construção do conhecimento revelando as porteiras abertas para diversos pesquisadores, pois sua natureza e cultura forma um tecido com diversas cores a serem percebidas por meio da pesquisa científica, seja ela na filosofia, educação, antropologia, geografia, geologia, cultura, biologia e outras áreas do conhecimento. O importante é ter como princípio a ética como fundamento para uma melhor compreensão, pois o sertão nordestino, por ser um lugar economicamente desfavorável com relação a outras regiões (sul e sudeste), e por ficar longe dos grandes centros urbanos, ainda é muito mal compreendido e estereotipado pelas pessoas que não conhecem sua dimensão ontológica e metafísica, onde a vida é plástica e se estende na expressão de uma simplicidade complexa, e por isso, não é fácil interpretá-lo e compreendê-lo, mas é possível vivê-lo.

\section{Referências}

ANDRIEU, Bernard. No Corpo da Minha Mãe (Tradução: Terezinha Petrucia da Nóbrega). Natal (RN): IFRN Editora, 2015.

BARROSO, Gustavo. Terra de Sol: Natureza e costumes do Norte. Rio de Janeiro (RJ): Livraria Francisco Alves, 1930.

BERGSON, Henri. A evolução criadora (tradução: Bento Prado Neto). São Paulo (SP): Folha de São Paulo, 2015.

CUNHA, Euclides da. Os Sertões. São Paulo: Cultural, 2003.

FERREIRA, Gilmar Leite. O Sertão educa. Curitiba (PR): Editora Appris, 2018.

FREIRE, Paulo. Ação Cultural: para liberdade e outros escritos. Rio de Janeiro (RJ): Paz e Terra, 2011.

HELLER, Andrés Alberto. Fenomenologia da expressão musical. Blumenau (SC): Letras Contemporâneas, 2006. 
MAURILIO, Ernani. Apresentação In: MELLO, Elomar Figueira. Auto da Catingueira. Vitória da Conquista (BA): Editora Rio do Gavião, 1984.

MELLO, Elomar Figueira. Cd Das Barrancas do Rio Gavião, São Paulo (SP), 1973. 1981.

Cd Fantasia leiga para um rio seco. Vitória da Conquista (BA): Gravadora Rio do Gavião,

MELLO FILHO, Luiz Emygdio de. Uma visão da Caatinga: Caatinga, Sertão, Sertanejos. Rio de Janeiro, (RJ): Alumbramento/Livroarte, 1994.

MERLEAU-PONTY, Maurice. Conversas (Tradução: Marina Apenzeller): São Paulo (SP): Martins Fontes, 2004.

Fenomenologia da percepção (Tradução: Carlos Alberto Ribeiro Moura). São Paulo (SP): Martins Fontes, 1999.

O Visível e o invisível (Tradução: José Artur Gianotti e Armando Mora de Oliveira). São Paulo (SP): Perspectiva, Cosac \& Naify, 2000.

NÓBREGA, Terezinha Petrucia. Uma Fenomenologia do Corpo. São Paulo (SP): Livraria da Física, 2010.

Sentir a Dança ou quando o corpo se põe a dançar. Natal (RN): IFRN Editora, 2015.

MORAES, Vinicius de. Apresentação In: MELLO, Elomar Figueira. Das barrancas do Rio Gavião. São Paulo (SP): Gravadora Polygram, 1973.

ZUMTHOR, Paul. Escritura e Nomadismo (Tradução: Jerusa Pires Ferreira e Sonia Queiroz). Cotia (SP): Ateliê Editorial, 2005.

Recebido em: 14/05/2020

Aprovado em: 08/12/2020 